\title{
Household Oeconomy and Chemical Inquiry
}

\author{
Simon Werrett
}

The history of the chemical laboratory was until recently quite obscure. But a number of studies have begun to reveal the material conditions and spatial configurations of chemical practice in a variety of settings in the period 1760 to 1840. Peter Morris's recent book The Matter Factory examines the laboratories of Lavoisier, Faraday and Liebig in this period, while a recent volume of Ambix considered eighteenth-century laboratories dedicated to chemical inquiry in, among other places, a porcelain manufactory, mining academy and assaying office. ${ }^{1}$ The focus of these studies has been purpose-built laboratories dedicated to chemical practice, and it has been suggested that chemistry could only take place in laboratories constructed for the purpose, since they needed to contain a furnace. ${ }^{2}$ While historians have clearly widened the repertoire of laboratories being studied from famous research institutions to military, industrial and academic sites, this chapter proposes that many sites of chemistry were not originally dedicated to chemical labors, and some were not laboratories at all.

Alix Cooper and Steven Shapin have noted that a great deal of early modern experimentation took place in people's homes. ${ }^{3}$ Cooper identifies the home as a key site of scientific inquiry and the family as the central unit in domestic knowledge-making. Cooper, Shapin and others have made social relations the focus of analysis for exploring the nature of knowledge-making in the home. Cooper considers how family life shaped early modern scholarly life, while Shapin demonstrated how expectations of gentlemanly conduct in the home

1 Peter Morris, The Matter Factory: A history of the chemical laboratory (London: Reaktion, 2015), esp. 19-20; John Perkins, ed. Sites of Chemistry in the Eighteenth Century, special issue of Ambix 6o, no. 2 (May 2013).

2 Ursula Klein, "The Laboratory Challenge: Some revisions of the standard view of early modern experimentation," Isis 99 (2008): 769-782, on 772-3.

3 Alix Cooper, "Homes and Households," Katharine Park and Lorraine Daston, eds., The Cambridge History of Science, Vol. 3: Early Modern Science (Cambridge: Cambridge Univ. Press, 2006), 224-237; Steven Shapin, "The House of Experiment in 17th-Century England," Isis 79 (1988): 373-404.

(C) SIMON WERRETT, 2018 | DOI 10.1163/9789004325562_003

This is an open access chapter distributed under the terms of the CC-BY-NC License. 
shaped experimental etiquette. ${ }^{4}$ This chapter also proposes that the home, among a variety of adapted spaces, continued to be an important site for chemical experimentation in the period 1760 to 1840 . It shows how chemical practices were shaped by the social order of the home, and particularly ideas of oeconomy, a body of knowledge and practice concerning the proper management of the household (and by extension, the state or even the universe). ${ }^{5}$ The focus here will be on Britain, and perhaps further research will reveal if similar relations to oeconomy existed elsewhere. Importantly, a fundamental focus of chemistry and oeconomy in Britain was the management of materials, and it is the material aspects of chemical activity in adapted spaces such as the home on which this chapter concentrates. Domestic chemistry and oeconomy were equally social and material practices, and this chapter might be seen as an exploration of sociomateriality, a term that reminds us that these arenas were always linked together in a rich variety of ways. ${ }^{6}$

Like the home itself, the material culture of chemical inquiry in this period could also be adapted, and might be said to have been in a constant state of flux, what the sociologist Karin Knorr-Cetina refers to as the "incompleteness" of objects. ${ }^{7}$ Chemical practitioners certainly purchased or made apparatus serving some specific chemical end from an instrument-maker, but they also turned a diverse array of household goods into apparatus for their experiments. The material form and uses of a household object or instrument unfolded over time. Even dedicated instruments were not static objects, but underwent alterations and repairs. Rather than overlook this as simple expe-

4 Gadi Algazi, "Scholars in Households: Refiguring the learned habitus, 1480-1550," Science in Context 16 (2003): 9-42; Frances Harris, "Living in the Neighbourhood of Science: Mary Evelyn, Margaret Cavendish and the Greshamites," Lynette Hunter and Sarah Hutton, eds., Women, Science, and Medicine 1500-1700: Mothers and sisters of the Royal Society (Stroud: Sutton Publishing, 1997), 198-217; Deborah E. Harkness, "Managing an Experimental Household: The Dees of Mortlake and the practice of natural philosophy," Isis 88 (1997): 247-262.

5 On oeconomy, see Lissa Roberts, ed., "Practicing Oeconomy in the Late Eighteenth Century," special issue of History and Technology 30 (2014); Keith Tribe, "Oeconomic History: An essay review," Studies in the History and Philosophy of Science 36 (2005): 586-597; Both Roberts and Tribe offer criticism of Margaret Schabas and Neil Di Marchi, eds., Oeconomies in the Age of Newton, Annual Supplement to History of Political Economy 35 (2003).

6 For discussion of the term sociomateriality, see Wanda J. Orlikowski, "Sociomaterial Practices: Exploring technology at work," Organization Studies 28 (2007): 1435-1448; It has of course long been an assumption of social studies of science and technology that the social and material are fundamentally linked.

7 See Karin Knorr-Cetina, “Objectual Practice," Theodore R. Schatzki, Karin Knorr-Cetina, Eike von Savigny, eds., The Practice Turn in Contemporary Theory (London: Routledge, 2001), 175-188, on 181-184. 
diency, this chapter suggests that practices of adaptation reflected the values of oeconomy. Oeconomy proposed that householders should care for material culture in the home, balancing the use of old goods with the purchase of new, and stewarding possessions through care, maintenance, and repairs which would ensure both the saving of time and money and the good order and harmony of the household and the environment within which it was embedded. What emerges then is a picture of chemical experimentation in the period 1760 to 1840 in which the re-use of old things was as significant a part of chemistry as the invention or consumption of new. ${ }^{8}$

A variety of people undertook chemical practices in the home, ranging from husbands and wives to servants and diverse networks and communities with whom the household interacted. Much of this work could be experimental and chemical, for example distilling and the preparation of medicines. This diversity will be reflected in the use of the term chemical practitioners, rather than chemists. "Material culture" was also diverse. It consisted of substances, the raw materials manipulated by chemical practitioners, instruments, the tools used to manipulate substances, and objects, the things chemists used besides instruments. The essay begins by examining concepts of oeconomy in the period before considering how the home was often a site for shared oeconomical and chemical practices. Householders strove to make the most of the material objects in their possession, and took care of those possessions to avoid them being damaged. Oeconomic and chemical literature offered diverse recipes for maintaining and repairing material possessions, and encouraged the re-use of broken objects and waste. The chapter concludes by considering how such an approach to materials was extended from the home to other sites such as the city and manufactories in the eighteenth and nineteenth centuries. Such extensions, which entailed rationalizations of labor and changes in scale had unintended consequences, contributing to pollution and a paradox about the value of re-using old materials which remains to this day.

\section{The Practice of Oeconomy: Managing the Household}

Early modern practices of oeconomy converged on the art of governance and could apply to the management of the family and household, the state or even the universe and divine "oeconomy of nature." There was no agreed-upon definition of oeconomy, and the many books on oeconomy that appeared in the

8 Chemistry fitted broader trends in the sciences, discussed in Simon Werrett, "Recycling in Early Modern Science," British Journal for the History of Science 46 (2013): 627-646. 
period 1760 to 1840 included an array of advice on cleaning, cooking, and maintenance, medicine and health, gardening, husbandry and agriculture together with the management of the family and servants. Genres of oeconomic literature were often divided according to gender, with women presented as being responsible for the internal management of the home and men for husbandry outside. Numerous books written by female authors gave advice to housewives on cookery, cleaning and medicine. But as Karen Harvey has argued, "any gendered division of tasks [in the home] was unstable, even in those books specifically intended for either male or female readers. ${ }^{\prime 9}$ Both men and women engaged in developing complex networks of exchange of recipes and practices related to chemical inquiry in the early modern period, and both men and women communicated practice orally, through letters or by keeping manuscript books. ${ }^{10}$ However, in this period the convention was for experimental inquiries into chemistry to be published by men, while women wrote and sometimes published recipes and hints for the preparation of medicines, food, and materials related to household maintenance. ${ }^{11}$ Bringing these apparently distinct literatures of household management and experimental inquiry together helps to make clear their interconnections in this period.

Not that oeconomy was even restricted to men and women. Oeconomy was not equivalent to economy. Although no strict contrast should be made between the two terms, oeconomy was not an abstract system of demand and supply or accounting of profit and loss, but a body of advice and examples relating to the prudent management of people and things. Both oeconomic and economic ideas related material culture, morals and social order, but economy came to do this in narrower terms than oeconomy during the nineteenth century. The subjects of oeconomy were typically humans, but numerous writers described the oeconomies of animals, birds and insects. Oeconomic thinking stressed the interrelatedness of all parts of the oeconomy of nature. "By the oeconomy of nature we understand the all-wise disposition of the creator in

$9 \quad$ Karen Harvey, The Little Republic: Masculinity and domestic authority in eighteenth-century Britain (Oxford: Oxford University Press, 2012), 27-28.

Elaine Leong, "Collecting Knowledge for the Family: Recipes, gender and practical knowledge in the early modern English household," Centaurus 55 (2013): 81-103; Elaine Leong, "Making Medicines in the Early Modern Household," Bulletin of the History of Medicine 82 (2008): 145-168; Sara Pennell and Elaine Leong, "Recipe Collections and the Currency of Medical Knowledge in the Early Modern 'Medical Marketplace," Mark Jenner and Patrick Wallis, eds., Medicine and the Market in England and its Colonies, c.1450-c.1850 (Basingstoke: Palgrave Macmillan, 2007), 133-152. 
relation to natural things, by which they are fitted to produce general ends, and reciprocal uses." ${ }^{12}$

In the period 1760 to 1840 , many chemical practitioners appear to have shared in the values of oeconomy through a prudent stewardship of materials. Since oeconomy often focused on the proper management of the home it is perhaps inevitable that its goals of frugality and care were reflected in chemical practices that often took place in people's houses. The domestic situation of chemical activities was itself in part an expression of such concerns. Certainly the need for a furnace meant some chemical laboratories required dedicated buildings, but in many cases instead of building new laboratories, chemical practitioners preferred to make use of existing and convenient sites, converting cellars, kitchens, parlors and outbuildings into experimental spaces. As the English chemist and publisher John Joseph Griffin wrote as late as 1834,

The notion, that a laboratory fitted up with furnaces and expensive and complicated instruments, is an absolute requisite for the proper performance of chemical experiments, is exceedingly erroneous. In fact, the truth is quite opposed to this opinion. "For general and ordinary chemical purposes," says Dr Henry, "and even for the prosecution of new and important inquiries, very simple means are sufficient: some of the most interesting facts of the science may be exhibited and ascertained with the aid merely of Florence flasks, of common phials, and of wine glasses. In converting these to the purposes of apparatus, a considerable saving of expense will accrue to the experimentalist; and he will avoid the encumbrance of various instruments, the value of which consists in show rather than real utility." It is a curious and instructive fact, that some of the most important discoveries in chemistry were made by persons who, either from choice, or motives of economy, used utensils of the very simplest character. The laboratory of the great Priestley cost a mere trifle; and it is well known how savingly Franklin went to work. ${ }^{13}$ History, Husbandry and Physick, trans. Benjamin Stillingfleet (London: R. and J. Dodsley, 1759), 31-108, on 31.

13 John Joseph Griffin, Chemical Recreations: A series of amusing and instructive experiments [...] to which are prefixed First Lines of Chemistry, seventh edition (Glasgow: R. Griffin and Co., 1834), 1; on Griffin see Brian Gee and William H. Brock, "The Case of John Joseph Griffin: From artisan-chemist and author-instructor to business-leader," Ambix 38 (1991): 29-62. 
The contents of Priestley's laboratories hardly cost a trifle, but his laboratories were all rooms in houses belonging to Priestley or his patrons. ${ }^{14}$ An engraved plate from Priestley's Experiments and Observations on Air (1774) showed the corner of his laboratory set up inside the orangery of Robert Adams' wing of Bowood House at Calne in Wiltshire, home to Priestley and his patron and employer the Earl of Shelburne in the 1770s. The fireplace, a round three-legged and a square table have all been put into experimental service, providing a source of heat and support for chemical instruments. Domestic and chemical functions overlapped in these spaces. Even the furnace, supposedly the marker of a dedicated chemical space, could double up as home heating. Priestley's inventory of the laboratory in his Birmingham home in the 1780 s included a furnace, "containing a large Copper Vessel also iron Tubes [...] adapted to it in order to warm the Laboratory." ${ }^{15}$ Chemical sites were also converted back into domestic space. A visitor to Priestley's Philadelphia residence in the nineteenth century noted: "His laboratory is now converted into a house for garden-tools! The furnaces pulled down, the shelves unoccupied! - the floor covered with Indian corn! A stranger might be inclined to say, "Sic transit gloria philosophiae" [Thus passes the glory of philosophy]."16

Sites of chemistry were thus routinely in flux, transformed between domestic, scholarly, and other uses. Cambridge colleges converted variously a cellar, a shed and an idle printing house to create new laboratories. ${ }^{17}$ Edinburgh professor of chemistry Joseph Black occupied the Library Range of the University's Old College from 1770 to 1781 , before moving to a purpose-built chemistry block. Archeology indicates that when both buildings were demolished in 1820, the larger stones were extracted from the rubble for re-use. ${ }^{18}$ From 1790

14 Priestley himself estimated the value of instruments and books in his Birmingham laboratory to be more than four thousand pounds. See Douglas McKie, "Priestley's Laboratory and Library and Other of his Effects," Notes and Records of the Royal Society 12 (1956): 114136.

15 Ibid., pp. 121-122.

16 John Finch, Travels in the United States of America and Canada, containing some Account of their Scientific Institutions (London: Longman, Rees, Orme, Brown, Green, and Longman, 1833), 316.

Kevin C. Knox, “'The Deplorable Frenzy': The slow legitimisation of chemical practice at Cambridge University," Mary D. Archer, Christopher D. Haley, eds., The 1702 Chair of Chemistry at Cambridge: Transformation and change (Cambridge: Cambridge University Press, 2005), 1-30, on 9 .

Tom Addyman, "Materia Chemica: Excavation of the early chemistry stores at Old College, University of Edinburgh." Typescript, thanks to Robert Anderson for providing this essay; see also Morris, Matter Factory, 70-72 (see note 1). 
James Watt experimented on pneumatic medicine, pottery and sculpture in a garret workshop at his home in Heathfield, Birmingham, a site which was later installed in London's Science Museum. ${ }^{19}$ Mixtures of domestic and experimental space prompted sociomaterial puzzles. Engagement with chemical commodities operated according to social divisions of private and public space and access in these sites. In 1794, Irish physician and chemist Bryan Higgins advertised a "Society for Philosophical Experiments" at his home at 13, Greek Street, London, where participants would be given access to his "extensive Apparatus" while "the best books on subjects under examination" would "always be ready for their perusal in the drawing-room." ${ }^{20}$ London chemist Frederick Accum "kept a considerable variety of apparatus" and a "working laboratory" in his house near Soho Square, which linked him to networks of instrument-makers and students. ${ }^{21}$ Male inquiry depended on female goodwill. In North America, Benjamin Silliman and Robert Hare maintained a chemical laboratory in the cellar-kitchen of their lodgings at 46, Walnut Street, Philadelphia, "conceded to us by the indulgence of our hostess, Mrs. Smith."22

\section{Making Use of the Home in Chemistry}

The kitchen could double up as a chemical laboratory, and as the oeconomy of the household overlapped with sites of chemistry, so oeconomical practices shaped or coincided with chemical practices. ${ }^{23}$ This might apply to shared techniques, but also to shared approaches to material culture. Chemical and oeconomic literature both described practices such as the distillation of spirits and the preparation of medications. Chemical practitioners applied to chemical instruments the same kinds of stress on stewardship and thrift that appeared in oeconomic literature on domestic management. Robert Dossie, author of a work on Agriculture and Other Oeconomical Arts, advised readers of his treatise on chemical arts The Elaboratory Laid Open of 1758 that proper maintenance of chemical instruments ensured, "considerable savings in

19 Ben Russell, James Watt: Making the world anew (London: Reaktion, 2014), 224-233.

20 Anon., Minutes of the Society for Philosophical Experiments and Conversations (London: T. Cadell Jr, and W. Davies, 1795), 6, 12. George Park Fisher, Life of Benjamin Silliman M.D., LL.D., 2 vols. (New York: Charles Scribner \& Co., 1866), vol. 1, 142.

22 Ibid., p. 103; Chandos Michael Brown, Benjamin Silliman: A life in the young Republic (Princeton, NJ: Princeton University Press, 2014), 108.

23 The kitchen was also an important space for the development of anatomy and dissection according to Anita Guerrini, "The Ghastly Kitchen," History of Science 54 (2016): 71-97. 
labour, fewel, and frequently the produce of the operation."24 This oeconomy of materials incorporated a diverse array of techniques, ranging from care over the human body to the maintenance, repair and re-use of various vessels and goods for chemical purposes. In some cases this might correspond directly with widely available oeconomic advice and in others chemical practice raised unique problems that demanded distinctive solutions.

One feature of oeconomic advice was to highlight the diverse uses to which materials could be put in the home, on estates and on farms. In his translation of Noel Chomel's Dictionaire oeconomique, or Family Dictionary, the Cambridge botanist and oeconomist Richard Bradley noted of the beech tree, "It's useful for many things" before listing the various uses of beech for making "Dishes, Trays, Rimbs for Buckets, Trenchers [...] Chairs, Stools, Shovels and SpadeGrafts." 25 There was value in the capacity of things to be converted to a wide array of uses. Certainly this was an era of expanding markets for luxury items. ${ }^{26}$ But oeconomy encouraged householders to balance the purchase of new goods with making good use of the old. An essay in the Gentleman's Magazine of ${ }_{1731}$ explained that oeconomy meant "Wisdom applied to the Practice of private Life; it is situated betwixt Profuseness and Avarice, and consists in a just Medium of Concern, as to exterior Goods, between being over Careful and having no Care at all." 27

Chemical practitioners faced with the execution of novel experiments might purchase or make new instruments for themselves but they also often adapted household items to chemical ends. The material culture of chemistry was a mixture of dedicated instruments purchased from specialist makers and a variety of household vessels and commodities such as teacups, saucers, bowls, dishes, wine glasses and furniture. Archaeological evidence supports this. Excavation in 2011 of the location where Joseph Black's chemical apparatus was stored in Edinburgh University uncovered "at least two mid-late 18th century black glass wine bottles" and,

24 Robert Dossie, The Elaboratory Laid Open, or, the Secrets of Modern Chemistry and Pharmacy Revealed (London: J. Nourse, 1758), 1; Robert Dossie, Memoirs of Agriculture, and Other Oeconomical Arts (London: J. Nourse, 1768).

25 "Beech-Tree," Noel Chomel, Dictionaire oeconomique; or, the family dictionary, trans. Richard Bradley, 2 vols. (Dublin: L. Finn, 1758), vol. 1, n.p.

26 See e.g. Sara Pennell, "Pots and Pans History': The material culture of the kitchen in early modern England," Journal of Design History 11 (1998): 201-216; Amanda Vickery, Behind Closed Doors: At home in Georgian England (New Haven \& London: Yale University Press, 2009).

27 Anon., [poss. Richard Burridge] “Oeconomie and Extravagance," The Gentleman's Magazine 1, no. 11 (November 1731), 489. 
[...] miscellaneous vessels of a [...] domestic nature, such as blue and white transfer-printed pearlware bowls and creamware jugs, that on the basis of residues present had evidently been employed in the preparation of chemical materials. ${ }^{28}$

Any number of such items are mentioned in chemical texts of the period. Less familiar household items also served chemistry. Firearms were a commonly adapted household item. Many early modern households contained muskets, pistols, or rifles, attested to by court records of firearm offenses and a 1541 statute which governed firearm ownership in England and encouraged a variety of subjects, "to have and keep in every of their houses any such hand-gun or hand-guns, of the length of one whole yard."29 Joseph Priestley's Birmingham inventory included a brace of pistols and a "Gun with a Bayonet." ${ }^{30}$ Gun barrels could then be adapted for use as electrical conductors or as vessels for heating. John White Webster proposed liberating gases from substances placed "in a gun barrel, the touch-hole of which has been accurately closed by an iron pin." ${ }^{31}$ Robert Dossie proposed making an alembic for distilling mercury with a covered copper or iron pan soldered to a gun barrel which sloped down into a "common water pail" filled with water. ${ }^{32}$ The Earl of Dundonald used gun-barrels to convey coal-gas for illumination in experiments at Culross Abbey near Dunfermline. ${ }^{33}$ Chemical apparatus was a bricolage of material elements, some old and some new, some dedicated and some adapted, an oeconomical mixture of the specialized and the re-purposed. As much as this period saw the construction of new instruments like the ice calorimeter, it also saw the thrifty re-use of many old ones.

28 Addyman, "Materia Chemica" n.p. (see note 18).

29 Quoted in Joyce Lee Malcolm, Guns and Violence: The English experience (Cambridge, MA: Harvard University Press, 2009), 50.

$30 \quad$ Priestley, quoted in McKie, “Priestley's Laboratory," p. 128 (see note 14).

$3^{1}$ John White Webster, A Manual of Chemistry: Containing the principal facts of the science, third edition (Boston: Marsh, Capen, Lyon and Webb, 1839), 106.

32 Robert Dossie, Institutes of Experimental Chemistry: Being an essay towards reducing that branch of natural philosophy to a regular system, 2 vols. (London: J. Nourse, 1759), vol. 1, $87-88$.

33 Thomas, Tenth Earl of Dundonald, The Autobiography of a Seaman, 2 vols., second edition (London: Richard Bentley \& Son, 1861), vol. 1, 39. 


\section{Avoiding Damage}

The care of materials was equally valued in domestic oeconomy and chemical inquiry. It was important to avoid damage to goods and the expense and trouble of repairing or replacing them. Householders could repair damaged household goods themselves or give them to street traders to fix. In her 1835 Modern Domestic Cookery and Useful Receipt Book Elizabeth Hammond explained how to mend broken iron pots, glass vessels and china, while recipes for repairs appeared in various works on chemistry. ${ }^{34}$ Homes were embedded in complex networks of artisans and waste traders who circulated between city streets and the countryside repairing or disposing of materials for a fee. Street traders included tinkers and chair menders, the former described as wearing an apron and broad-brimmed hat, carrying saucepans, a hammer and crying "pots to mend!"

Damage during chemical experiments could be of various sorts. Instruments might be "deranged" or broken, substances could be corrupted or polluted through unwanted mixing, and practitioners' bodies might be hurt or wounded by corrosive or explosive reactions. Much chemical practice centered on the avoidance of such problems. Good design with appropriate materials and careful storage, cleaning and maintenance helped to ensure the integrity and longevity of instruments.

Practitioners reckoned making instruments durable and sturdy was critical. This applied first and foremost, according to Dossie, to the principal instrument of the chemical laboratory, the furnace,

[...] they should be well designed, and judiciously executed; otherwise their defects greatly enhance the expense, and frustrate the intention, of the operations they are to perform; besides their being extremely liable to become, in a very short time, out of repair and uselessly ruinous. ${ }^{35}$

Dossie identified types of furnaces that were liable to damage or difficult to repair and warned against installing them. ${ }^{36}$ "Damage" for Dossie was a matter of both financial loss and social disorder. Damage to flour-grinding mills or

34 Elizabeth Hammond, Modern Domestic Cookery and Useful Receipt Book adapted for Families in the Middling and Genteel Ranks of Life (London: Dean and Co., 1835), 246-7.

35 Dossie, Elaboratory Laid Open, pp. 3-4 (see note 24).

36 Ibid., pp. 9-10. 
that caused by vermin or disease in sheep were among "the greatest evils [...] which the public sustains." ${ }^{37}$ Derangement was moral and material.

In domestic and chemical practices, glass provided the principal material for ensuring substances were kept free from pollution and corruption. In 1780 The Farmer's Wife; Or complete country housewife explained that, "Stone or glass jars are the most proper vessels in which to make and keep pickles; for common earthen vessels are soon penetrated by the vinegar and salt." ${ }^{38}$ As Marie Thébaud Sorger reminds us, glass vessels, including various jars and tubes, were used in chemical experiments to collect and contain substances such as airs, managed with glass stirring rods, thermometers, and stoppers. ${ }^{39}$ Vessels should be made to minimize the risk of damage. Dossie proposed that glass receivers be made larger than those in common use.

A greater quantity of condensing surface [renders] the operation both more profitable and safe, as it prevents the forcing of the lute, and the escape of the vapour; as well as the hazard of bursting the vessels, on the raising the fire too high. ${ }^{40}$

Chemical practice routinely threatened derangement. Chemistry by its very nature involved unpredictable reactions which were liable to break or damage instruments. To avoid cracking vessels heated to high temperatures they could be placed in baths. Thomas Garnett explained in his chemical lectures of the 179os,

Chemical vessels may be plunged [...] in a pot placed over the furnace, containing sand, water, or other matter capable of sustaining heat. These substances interposed between the vessel and the fire, compose [...] a bath, and are very helpful in imparting an uniform heat [...] Without this contrivance, glass vessels would often fly and crack. ${ }^{41}$

37 Ibid., p. 177 .

38 Anon., The Farmer's Wife; Or complete country housewife (London: Alex Hogg, c.1780), 57.

39 See Chapter 3. Robert Harrington, A Treatise on Air, containing New Experiments and Thoughts on Combustion; Being a full investigation of Mr. Lavoisier's system (London: T. Evans, 1791), 194; William Nicholson, The First Principles of Chemistry (London: G.G.J. and J. Robinson, 1792), 48.

40 Dossie, Elaboratory Laid Open, p. 29 (see note 24).

41 Thomas Garnett, Outlines of a Course of Lectures on Chemistry (Liverpool: J. M'Creery, 1797), 47 . 
Protecting instruments with cases, boxes, and crates for storage and transport was another solution to such problems. Chemical goods routinely circulated between homes in the hands of potentially unreliable couriers and post-men. ${ }^{42}$ Joseph Priestley shared many chemical practitioners' anxieties over glassware sent to him by mail coach. In 1781, he wrote to Josiah Wedgwood from Birmingham about two boxes of retorts that Wedgewood had sent to him, "The cover of the larger box was quite off, and ten of the retorts broke, most of them so as to be of no use at all." ${ }^{43}$ Things got even worse when Priestley moved to North America. ${ }^{44}$

Managing damage was "sociomaterial", involving both human and artificial bodies. Chemical instruments were fragile and had to be carefully looked after. The same was true of practitioners' bodies, which they equally sought to preserve from damage. Oeconomy concerned health and safety as much as the saving of expense. Worcester surgeon William Sandford described his collection of medical advice on "the oeconomy of health" as an effort "to enable the uninformed in medical knowledge, to understand in some degree, upon what principles life is sustained, and how it may probably be prolonged, with ease and comfort to ourselves, and benefit to our posterity." ${ }^{\prime 5}$ The bodies of chemical practitioners also required sustaining. Explosions, broken glass, electric shocks, and corrosive chemicals all threatened their integrity. To protect his eyes during experiments James Watt adapted ordinary spectacles with flat glass lenses. ${ }^{46}$ Michael Faraday recommended wearing "glass masks, goggles, \&c." when making experiments with carbonic acid. ${ }^{47}$ Chemists invoked theory when determining safety techniques. Kings College London professor of chem-

42 Kenneth Ellis, The Post Office in the Eighteenth Century: A study in administrative history (Oxford: Oxford University Press, 1958).

43 Joseph Priestley to Josiah Wedgwood, August 8, 1781, in Joseph Priestley, Scientific Correspondence of Joseph Priestley. Ninety-seven letters addressed to Josiah Wedgwood, Sir Joseph Banks [...] Dr. Benjamin Rush, and others, ed. Henry Carrington Bolton (New York: privately printed, 1892), 29-30, on 29.

44 See e.g. Joseph Priestley to John Vaughan, March 21, 1799. Joseph Priestley Papers, American Philosophical Society, B P931.

William Sandford, A Few Practical Remarks on the Medicinal Effects of Wine and Spirits; With observations on the oeconomy of health (Worcester: J. Tymbs, 1799), vii; see also e.g. Andrew Harper, The Oeconomy of Health, or, a Medical Essay: Containing new and familiar instructions for the attainment of health, happiness and longevity (London: C. Stalker, c. 1785$)$.

46 Watt's safety goggles, Watt's Workshop Collection, Science Museum, London, Inventory number 1926-1075/440.

47 Michael Faraday, Experimental Researches in Chemistry and Physics (London: R. Taylor and W. Francis, 1859), 92. 
istry John Frederic Daniell described the way glass halted the passage of radiant or "dark" heat and explained how, as a result, "This property of glass is sometimes usefully employed where it is desirable to see the light of a fire without being incommoded by the heat; [so] glass screens are used to protect the eyes when it is necessary to inspect the action of a hot furnace." 48

Chemistry could cause severe damage to the hands. In 1837 a young Matthew Arnold was taken away from Winchester College after severely burning his hand in a chemistry class (he nearly lost two fingers). ${ }^{49}$ Hands were protected with gloves. Since phosphorus was "sometimes thrown out of the mortar" during its preparation, American surgeon John Lee Comstock warned chemistry students that "it is therefore advisable to protect the hand with a glove, and keep the face out of the way."50 But there were no cheap, disposable gloves available at the turn of the nineteenth century, and gloves might hinder dexterity. Experimenters thought twice before exposing gloves to damage. In 1816 Richard Davenport experimented on the communication of heat in boiling tar. Although he was convinced that his gloved hand would not be "dreadfully burnt" if he plunged it into boiling tar, Davenport hesitated. "Not choosing to sacrifice a pair of gloves to the trial of an effect I had no belief in, I wrapped a newspaper double about my hand, and plunged it in up to the wrist. I retained my hand in the tar longer than I could when naked without feeling any pain."51

\section{Maintenance}

Chemical practice was a trade-off between damage, durability, and discovery, where by necessity the circulation of materials, whether in the laboratory or across countries or continents, could and did break things. In addition to these labors to keep things from derangement, chemical practitioners went to great lengths to repair things if they did break. Repair constituted a major part of enlightened artisanry and many "makers" spent more time cleaning and repairing goods than making them. As David Edgerton has argued, repair and

48 John Frederic Daniell, An Introduction to the Study of Chemical Philosophy: Being a preparatory view of the forces which concur to the production of chemical phenomena (London: J.W. Parker, 1839), 188.

49 My thanks to Geoffrey Day of Winchester College who provided the letter from Arnold to his parents, dated April 7, 1837 .

50 J.L. Comstock, A Grammar of Chemistry, adapted to the Use of Schools and Private Students, second edition (Hartford: S.G. Goodrich, 1825), 30-31.

$5^{1} \quad$ Richard Davenport, "Curious Experiments on Boiling Tar," Annals of Philosophy; or, Magazine of Chemistry 9 (Jan-Jun 1817): 111-114, on 114. 
maintenance "are the most widespread form of technical expertise" because the number of users typically far outweighs the number of producers of technical artifacts. ${ }^{52}$ Oeconomical treatises discussed the cleaning and repair of buildings and household goods. ${ }^{53}$ Repair work was also widespread in chemistry both because practitioners needed to repair their own vessels, and because they offered techniques and recipes to others for making repairs.

Adhesives, for example, fascinated oeconomic writers and chemical practitioners. Bradley's translation of Chomel's Dictionaire oeconomique included numerous glue recipes and advice on repairing broken glass with a mixture of liquid fat and varnish. ${ }^{54}$ Mrs. Fisher explained in the Prudent Housewife how to make cements and glues for sticking stone and glass using a paste of flint powder combined with melted white rosin. ${ }^{55}$ Robert Dossie also investigated various cements, pastes, lutes, sizes and glues, and published new recipes in works on industrial arts and chemistry. ${ }^{56}$ Dossie's recipes were intended to allow repairs of common household commodities like china and porcelain, or specialized chemical glassware and instruments. For the chemist, he provided a recipe,

[...] for the repairing the cracks, and replacing the broken pieces, of receivers, or other glass vessels, which admit of being used after they are in that condition; and this, judiciously applied, in an elaboratory, where many such vessels are used, will make a considerable saving. ${ }^{57}$

Filling a crack with a linen rag soaked in a mixture of grated Suffolk cheese, powdered quicklime and milk, "will make the part equally strong, and sound, with the rest of the vessel. ${ }^{58}$ Other recipes ranged from the simplest paste made with flour and water to cements for fixing chemical vessels using linseed meal, whiting, gum senegal, Windsor loom and Sturbridge clay, or mixtures of

$5^{2}$ David Edgerton, The Shock of the Old: Technology and global history since 1900 (Oxford; New York: Oxford University Press, 2007), 80. See e.g. John Mordant, The Complete Steward: Or, the duty of a steward to his lord, 2 vols. (London: W. Sandby, 1761), vol. 1, 389 .

54 See "Glass," and "Glue" in Chomel, Dictionaire oeconomique, vol. 1, n.p. (see note 25).

55 Mrs. Fisher of Richmond, The Prudent Housewife; Or, complete English cook, for town and country, fourth edition (London: T. Sabine, 1788), 80.

56 e.g. Dossie, Elaboratory Laid Open, pp. 49-52 (see note 24); Robert Dossie, The Handmaid to the Arts, 2 vols. (London, 1758), vol. 2, 21-31.

57 Dossie, Elaboratory Laid Open, p. 52 (see note 24).

$5^{8}$ Ibid. 
quicklime and egg whites. ${ }^{59}$ Cements were applied with a stick or an old tobacco pipe. ${ }^{60}$

Chemical practitioners avoided damage, and repaired things when this was unavoidable. And if instruments could not be repaired, they could still be made serviceable. In the inventory of electrical instruments in his Birmingham laboratory Priestley included "About forty square feet of coated Jars which had been cracked by Explosions but were of some use."61 When no longer useable, broken items could be converted to some other use. Lavoisier explained in Elements of Chemistry that to contain liquids for distillation, "The best utensils for this purpose are made of the bottoms of glass retorts and matrasses." ${ }^{\prime 2}$ A heated iron ring connected to a wooden handle could be placed around the broken vessel to make it useable. ${ }^{63}$ This practice of using old vessels even after they were broken had a long tradition, extending well before and after Lavoisier's time. The archaeology of chemical remains related to Joseph Black at Edinburgh revealed "assorted bottle bases containing residues." ${ }^{4}$ In 1830, Michael Faraday wrote that "very useful glass dishes and capsules are made out of old retorts, receivers, and flasks." ${ }^{65}$ Harvard professor of Chemistry John White Webster's 1839 Manual of Chemistry explained that earthenware vessels could be used to liberate gases from substances if they were coated and luted before heating to prevent cracking,

[...] horse dung, chopped hay, horse hair, and tow cut short may be incorporated with the lute. The addition of sand, renders the lute more fusible, and is not applicable when very high temperatures are to be sustained. In such cases fragments of broken glass pots, or of broken crucibles, may be used, being first well pulverized. ${ }^{66}$

Here broken items were used to prevent further items breaking. Fragments served as a material for making new instruments, for lutes, and also to provide

\footnotetext{
59 Dossie, Handmaid to the Arts, vol. 2, p. 26 (see note 56).

60 Ibid., vol. 2, pp. 26-28.

61 Priestley, quoted in McKie, "Priestley's Laboratory," p. 117 (see note 14).

62 Antoine-Laurent Lavoisier, Elements of Chemistry, trans. Robert Kerr (Edinburgh: William Creech, 1790), 377 .

63 Ibid.

64 Addyman, "Materia Chemica" n.p. (see note 18).

65 Michael Faraday, Chemical Manipulation: Being instructions to students in chemistry on the methods of performing experiments of demonstration, second edition (London: John Murray, 1830$), 168$.

66 Webster, A Manual of Chemistry, p. 106 (see note 31).
} 
physical support. Samuel Parkes, London chemical manufacturer and author of a Chemical Catechism, used broken glass to produce phosphoric acid by exposing sticks of phosphorus to the air inside a glass funnel. "Two or three pieces of broken glass placed in the neck of the funnel to support the phosphorus, and a small quantity of distilled water put into the receiving bottle, complete this simple apparatus." ${ }^{\prime 6}$

\section{Waste}

Materials and instruments that really could not be used again might be discarded as waste and swept out of the house as dust. At that point they returned to wider circulations of used materials that characterized early modern states. Few materials at this time were not re-used. Many people made a living trading in old and discarded goods in the early modern period. Since the fourteenth century in many European cities, a community of scavengers were employed by municipal authorities to roam the streets with carts collecting materials. Coal ashes, bones, metals, rags, cinders, night-soil, metals and shells were all gathered and refashioned into new products. ${ }^{68} \mathrm{Chemical}$ practitioners engaged with these trades. In October 1768, Joseph Black told James Watt that he had asked Ninian Hill, owner of a laboratory in Glasgow, to send Watt some things to be packed and sent by carriers to Black in Edinburgh.

[...] among these are an absurd sort of still and a tall head to it both of copper - the tall head you may sell as old Copper - the Still or Body, I wish to have opened above by taking off the top of it which is soldered on only with soft solder and that top is also to be sold as old Copper - the rest of the Body will serve me as a boiler and may be sent packed full of the other things. ${ }^{69}$

Nothing was wasted as Black cannibalized the still and sold the head.

67 Samuel Parkes, The Chemical Catechism: With notes, illustrations, and experiments, fifth edition (London: Lackington, Allen and Co., 1812), 190.

68 On early modern waste disposal, see Emily Cockayne, Hubbub: Filth, noise and stench in England, 1600-1770 (New Haven: Yale University Press, 2007), 183-91.

69 Joseph Black to James Watt, Edinburgh, $3_{1}$ October 1768, in Eric Robinson and Douglas McKie, eds., Partners in Science: Letters of James Watt and Joseph Black (London: Constable, 1970), 15 . 
Chemical practitioners also made it their business to encourage others to make the most of waste, promoting the same oeconomic principles that guided their day-to-day interactions with materials. Practitioners argued that the application of chemistry reduced waste and improved arts. In 1800, for example, the Scots periodical writer Robert Heron praised Lavoisier's chemistry for improving the art of bleaching, which was, he said, "till lately, extremely tedious, and required long labour, a great waste of time, and an extraordinary consumption of expensive materials. The waste of lime, alkali, acids, fewel, was very great." Heron went on to argue that cookery, a prominent oeconomic practice, if subjected to more chemical science, could equally become less wasteful, "how often are the best pieces of animal food, at present, wasted? [...] much improvement might be made by a due application of chemical skill."70

Chemical authors also promoted the idea that chemistry could reveal new uses for byproducts and waste materials. The re-use of old materials was of course common in many chemical trades, and often international in scope. As Joppe Van Driel has documented, in the Netherlands ashes and urban filth were transported to rural areas to provide fertilizer for new raw materials for urban factories. In the name of 'sustainability' (duurzaamheid), administrators, entrepreneurs and chemists collaborated to steward materials. ${ }^{71}$ In Britain, paper was made from old rags imported from Spain, Russia, and elsewhere; tanning used dogs' dung picked up off the streets by female "pure-finders"; copperas or green vitriol production mixed old iron with a liquor derived from pyrites to produce copperas crystals. Old plaster was used to manufacture niter; old bones were used to make glue. ${ }^{72}$ Chemical authors articulated the practices of these manufactures and claimed to be able to improve them. Robert Dossie described how to make spirit of hartshorn (the horns of a male deer), used as a detergent for removing stains, by distillation in his explicitly titled Elaboratory Laid Open. Place pieces of hartshorn in a still and gradually

70 Robert Heron, Elements of Chemistry: Comprehending all the most important facts and principles in the works of Fourcroy and Chaptal (London: T.M. Longman and O. Rees, 1800), 548,586 .

71 Joppe van Driel, "Ashes to Ashes: The stewardship of waste and oeconomic cycles of agricultural and industrial improvement, 1750-180o," History and Technology 30 (2014): 177206; see also Joppe van Driel and Lissa Roberts, "Circulating Salts: Chemical governance and the bifurcation of 'nature' and 'society', Eighteenth-Century Studies 49 (2016): 233-63. Anon., The Art of Tanning and Currying Leather: With an account of all the different processes made use of in Europe and Asia (London: J. Nourse, 1780), 142, 209-10; Tim Allen, Mike Cotterill, Geoffrey Pike, "The Kentish Copperas Industry," Archeologia Cantiana 122 (2002), 319-334; on niter, see Antoine Baumé, A Manual of Chemistry; Or a brief account of the operations of chemistry and their products (Warrington: W. Eyres, 1778), 269. 
increase the heat from a fire. An oil, salt and spirit would result, of which "let the spirit, and salt, be mixt together again; and distilled with a gentle heat, and they will both rise purer. If this operation be several times cautiously repeated [...] the spirit will become limpid as water, and have a grateful smell."73

Others identified further waste substances which could be used for oeconomic ventures such as agriculture. Chemical writers criticized the poor practices of traditional managers of waste. In the Edinburgh Magazine of 1796 Thomas Butterworth Bayley, penal reformer and founder of the Manchester Literary and Philosophical Society, advocated to the Manchester Agricultural Society the use of waste materials for manure. Bayley lambasted farmers,

[...] of all ranks, carrying on their lands, at a great expense of labour, time, and money, vast quantities of stable dung, whilst at home they overlook and neglect the most easy, plain, and cheap methods of accumulating manures, and enriching their farms. ${ }^{74}$

Bayley then identified wastes that could be turned into valuable commodities, including mud, mixed with lime, street sweepings and ashes, night soil, bones, sweepings of cotton and woolen mills, sea-weed, sea shells, river weeds, spent tanner's bark, decayed vegetables, water from steepings of flax and hemp, bleachers' ashes, soap suds and ley. ${ }^{75}$ Also in the 1790 , following the Scottish proverb that "muck is the mother of the meal chest", Archibald Cochrane, Earl of Dundonald, explored the potential of various wastes as fertilizers in A Treatise, Shewing the Intimate Connection that Subsists Between Agriculture and Chemistry. Chemical substances might be turned to good use, "Muriat of Magnesia [...] may be procured in great quantities from the bitter refuse liquor which at present runs to waste at the salt works." ${ }^{76}$ Coal-gas, another product of interest to Cochrane, was a byproduct of the distillation of coal into coke, and remained a waste product of that process, liberated into the air, through the eighteenth century. In the early nineteenth century, however, the German inventor Frederick Winsor competed with Scots engineer William Murdoch to

\footnotetext{
73 Dossie, Elaboratory Laid Open, p. 1 (see note 24).

74 T.B. Bailey [Bayley], "Thoughts on Collecting Substances for Manure," Edinburgh Magazine, or Literary Miscellany (Oct 1796): 291-293, on 291.

75 Ibid., pp. 291-293.

76 Archibald Dundonald, Earl of Cochrane, A Treatise, Shewing the Intimate Connection That Subsists Between Agriculture and Chemistry (London: J. Murray and S. Highley, 1795), 73, 90.
} 
use coal gas as an illuminant. Both Winsor and Murdoch sought to give credibility to their enterprises by evoking scientific principles and backing. ${ }^{77}$

Such enterprises thus saw chemists seeking to co-opt traditional areas of artisanry, agriculture, and manufactures in the name of the same oeconomic goals of managing materials, reducing waste, and saving money that marked household approaches to materials and experimentation. Chemical practitioners frequently moved between manufacturing and domestic contexts in pursuit of these enterprises. Dundonald spent considerable wealth scaling up chemical manufacturing enterprises on his estates in Scotland, and passed regularly between his large-scale concerns and smaller home laboratories like that of James Watt in Birmingham. ${ }^{78}$ Dundonald ruined his finances on this enterprise, suggestive of the way oeconomic motives might differ from the simply "economic". ${ }^{79}$ Watt meanwhile constructed prototypes of inventions such as the separate condenser from left-over pipes and syringes, before deploying them in steam manufactures. ${ }^{80}$ Gas-lighting schemes also moved between the home and larger urban sites. Winsor first offered customers novel stoves producing light and heat with gas, fitted inside a single house, which were eventually connected through a network of pipes and supplied by gasometers to produce a network on an industrial scale. ${ }^{81}$

In one case at least, claims that chemistry might improve the management of waste went alongside changes from oeconomic to economic language. ${ }^{82}$ Oeconomy and economy shared some features but the rational management characteristic of economy focused on quantitative measures of financial profit and loss, numerical accounting, and the supposedly rational principles of the unfettered market. The mathematician Charles Babbage famously reckoned a

77 Simon Werrett, "From the Grand Whim to the Gasworks: Philosophical fireworks in Georgian England," Lissa Roberts, Simon Schaffer, and Peter Dear, eds., The Mindful Hand: Inquiry and invention from the late Renaissance to early industrialisation (Amsterdam and Chicago: Edita; University of Chicago Press, 2007), 325-48.

78 Thomas Barnes Cochrane Dundonald and Henry Richard Fox Bourne, The Life of Thomas, Lord Cochrane, Tenth Earl of Dundonald, completing "The Autobiography of a Seaman", 2 vols. (London: R. Bentley, 1869), vol. 2, 223.

79 The theme is elaborated in John Christie's contribution to this volume.

$80 \quad$ Russell, James Watt (see note 19).

81 Leslie Tomory, Progressive Enlightenment: The origins of the gaslight industry, 1780-1820 (London; Cambridge, MA: MIT Press, 2012).

82 For a fuller discussion of the shift from oeconomy to economy, see Joppe Van Driel, "The Filthy and the Fat: Oeconomy, chemistry and resource management in the age of revolutions," (PhD Thesis, University of Twente 2016); and Simon Werrett, Thrifty Science (Chicago: University of Chicago Press, forthcoming). 
more careful accounting of the value of waste was necessary to improve manufactures. In an appendix to his $183^{2}$ Economy of Machines and Manufactures, Babbage gave precise accounts of the "profitable conversion of substances apparently of little value" at a horse-slaughtering yard in Montfaucon near Paris. Reckoning the value of hair, skin, blood, hoofs, fat, flesh, tendons, and bones converted into animal food, manure, combs, lamp fuel, and other products, Babbage demonstrated that a "dead horse [...] which can be purchased at from 8.s. 6.d. to 12 s., produces from £2. 9.s. to £4. 14.s." ${ }^{83}$ In contrast with Babbage's optimism over the economics of waste, others were more cautious. Economists questioned whether the efficient use of materials was actually beneficial. In 1865, University College London economist William Stanley Jevons argued in The Coal Question that the creation of increasingly efficient engines had not led to a reduction in the consumption of coal but on the contrary to a great increase, because increased efficiency lowered the cost of engines and encouraged their consumption. As Jevons concluded, "It is wholly a confusion of ideas to suppose that the economical use of fuel is equivalent to a diminished consumption. The very contrary is the truth." ${ }^{84}$ The efficient use of waste might generate profits and growth, but it might equally create more problems than it solved.

\section{Conclusion}

A common narrative identifies a "revolution in chemistry" in the period 1760 to 1840 and identifies this revolution with radical innovation. The rhetoric of contemporaries and historians often equated this innovation with a throwing out of the old. John Joseph Griffin explained to readers of his Chemical Recreations in 1834, "To reform the nomenclature of chemistry, is to cleanse the Augean stable, where rubbish has been accumulating for forty years." ${ }^{85}$ Georges Cuvier reckoned Henry Cavendish and Torben Bergman had "cleared that Augean stable, still overspread with the rubbish of hermetical philosophy."86 Historians follow the same lead. "Lavoisier" wrote J.D. Bernal in his 1965 Science in History

83 Appendix to Charles Babbage, The Economy of Machines \& Manufactures, third edition (London: J. Murray, 1846), 393-96.

84 William Stanley Jevon, The Coal Question (London: MacMillan, 1865)

85 Griffin, Chemical Recreations, p. iv (see note 13).

86 Georges Cuvier, "Biographical Memoir of Henry Cavendish," Edinburgh New Philosophical Journal 9-10 (1828): 209-222, on 217. 
"made a clean sweep of all the old time-hallowed chemical nomenclature."87 "The Chemical Revolution," Mi Gyung Kim writes more recently, "was successful in cleaning the attic and thereby putting the house in order." 88

The household and its maintenance remain potent locations for making sense of chemical practice. However, chemical inquiry understood from a sociomaterial perspective in the period 1760 to 1840 was by no means about throwing out the old. Historians focused on the dedicated culture of chemistry, on materials and locations which were designed and built exclusively for chemical inquiry, have overlooked a widespread practice of adapting and converting spaces and goods to chemical ends during these decades. Early moderns, like contemporary sociologists, viewed much material culture as "incomplete", not dedicated to a single end but pregnant with possible uses. Kitchens, cellars, wine bottles, broken saucers, gun barrels, and the hints and recipes that cleaned, cared for and repaired them were as much a part of chemical experimentation as specialized apparatus like the furnace or crucible and even the latter could be altered or repurposed according to need.

Making the household and other adapted spaces the focus in this essay has revealed a set of practices and approaches to material culture that were intimately connected with and often corresponded to practices of oeconomic household management. Oeconomic concerns, shared among family members, sought to balance the consumption and use of new goods with the careful stewardship of the old, maintaining and making good use of existing possessions where possible. This led to savings of money and time, but beyond narrow conceptions of profit and loss, it established good order and provided a model for the management of other arenas of life. Applied to chemistry, oeconomics regulated a diverse body of spaces and materials that were the location of much experimentation.

\section{Acknowledgments}

My thanks to Lissa Roberts, John Perkins, and the members of the 'Situating Chemistry' project for their support and constructive commentary throughout

87 J.D. Bernal, Science in History, 4 vols. (Harmondsworth: C.A. Watts, 1965), vol. 3, 451; "Lavoisier soon realized that the confusion of alchemical terminology had to be swept away along with the phlogiston theory." Sarah Regal Riedman, Antoine Lavoisier: Scientist and citizen (London: Abelard-Schuman, 1967), 141.

Mi Gyung Kim, Affinity: That elusive dream (Cambridge, MA: MIT Press, 2003), 393. 
the development of this essay. Part of this essay was written as a fellow at the Beckman Center for the History of Chemistry at the Chemical Heritage Foundation in Philadelphia, and with the support of the Rachel Carson Center for Environment and Society in Munich for which support I am most grateful. 